\title{
Aplicação do Mapeamento do Fluxo de Valor na Indústria de Alumínio
}

Application of Value Stream Mapping in the Aluminum Industry

\author{
Camila da Silva Oliveira ${ }^{1}$ \\ Lara Calado ${ }^{1}$ \\ ${ }^{1}$ Escola Politécnica de Pernambuco, Universidade de Pernambuco, Recife, Brasil, \\ E-mail do autor principal: Camila da Silva Oliveira camilasiol@hotmail.com
}

\section{Resumo}

Nos dias de hoje, novas metodologias estão sendo adotadas por empresas de manufatura para prover a crescente necessidade de melhores resultados operacionais, pois o mercado cada vez mais alcança patamares altos de competitividade. De acordo com este contexto, diversas ferramentas surgiram buscando produtividade e qualidade com menor custo. Dentre elas pode-se destacar o Mapeamento de Fluxo de Valor (MFV). A construção do MFV auxilia na visualização de todo o processo, identificando os desperdícios, e proporcionando oportunidades de melhoria neles. O objetivo deste trabalho consiste em descrever e analisar os conceitos do Sistema Toyota de Produção e aplicação da ferramenta MFV no processo de uma indústria de alumínio. O estudo de caso apresenta os ganhos atingidos com a implementação da ferramenta no processo, confirmando as vantagens do uso dessa ferramenta apontadas na literatura.

Palavras-Chave: Mapeamento de Fluxo de Valor, Indústria de Alumínio, produtividade, perdas.

\begin{abstract}
Nowadays, new methods are being adopted by manufacturing companies to provide the growing need for better operating results, as the market increasingly reaches high levels of competitiveness. According to this connection, various tools have arisen aiming productivity and quality at lower cost. Among them we can highlight the Value Stream Mapping (VSM). The construction of the VSM assists in visualization of the entire process by identifying waste and providing opportunities for improvement therein. The objective of this study is to describe and analyze the concepts of the Toyota Production System and implementation of VSM tool in the process of an aluminum industry. The case study presents the gains achieved with the implementation of the tool in the process, confirming the advantages of using this tool mentioned in the literature.
\end{abstract}

Key-words: Value Stream Mapping, Aluminium Industry, productivity, losses. 


\section{Introdução}

A globalização e o mercado competitivo têm impulsionado as empresas a uma busca contínua de melhores resultados nos seus processos, desenvolvendo atividades que proporcionem vantagem competitiva, eficiência, com menor custo e maior qualidade, para assim oferecer um melhor produto ou serviço. Tudo isto, sem prejudicar a saúde e a segurança dos seus colaboradores.

Para tentar continuar atuando no mercado, os propósitos da corporação não devem depender apenas do seu sistema produtivo, mas também em ser competitivo em termos de preços, qualidade, além de tentar minimizar ao máximo o tempo de entrega do produto final, garantindo, principalmente, a satisfação do cliente.

As empresas precisam trabalhar com uma produção enxuta, buscando a redução de seus custos de produção, reduzindo as atividades que não agregam valor ao produto ou processo, ou seja, reduzindo os desperdícios desde o recebimento da matéria-prima até a expedição do produto final. Portanto, a problemática a ser analisada é o excesso de desperdício de tempo, matéria-prima e informações do processo.

Rother \& Shook [1] afirmam que se pode utilizar o Mapeamento de Fluxo de Valor (MFV), como uma ferramenta da produção enxuta, para melhorar a eficiência de uma empresa, quando usada para diminuir a perda do processo. Apesar da aplicação inicial voltada para manufatura, esta ferramenta pode ser utilizada para outros seguimentos, aplicando o estado inicial do processo pesquisado e construindo o estado futuro pretendido.

Neste contexto, é apresentado neste trabalho um estudo da ferramenta de MFV no processo de laminação, numa indústria de alumínio, analisando e identificando oportunidades de melhoria nos tempos de produção e assim, eliminação de desperdícios na cadeia produtiva.

\section{Metodologia}

No desenvolvimento deste trabalho é realizada uma pesquisa bibliográfica, para complementação da base teórica relevante para o tema estudado. Adicionalmente, a pesquisa tem como finalidade, a aplicação, através do estudo da implementação e desenvolvimento do tema em uma indústria de alumínio. Segundo Marconi e Lakatos [2], a pesquisa aplicada é caracterizada pelo seu interesse prático, isto é, que os resultados sejam voltados para solução de problemas reais. Foi utilizada a abordagem combinada explanatória, que apresenta, primeiramente, a análise de dados mensuráveis por meio de indicadores que mostrem a situação anterior à implantação, e após a mesma, com os dados obtidos é aplicada a abordagem qualitativa para poder melhor entender comportamentos e resultados que necessita de uma melhor análise. O estudo é o descritivo, em que busca descrever as características, propriedades ou relações existentes no fenômeno investigado. Este tipo de pesquisa caracteriza-se frequentemente como estudos que procuram determinar status, opiniões ou projeções futuras nas respostas obtidas [3].

Neste trabalho foi utilizado o estudo de caso como principal modalidade de pesquisa, sendo escolhida uma empresa alvo onde foi aplicado o mapeamento de fluxo do valor de uma linha de produção, permitindo conhecer as oportunidades de melhoria do processo.

Neste estudo foi empregada a técnica de pesquisa de documentação indireta, que tem o intuito de recolher informações prévias sobre o campo de interesse, fazendo levantamento de dados de variadas fontes. É utilizada a pesquisa bibliográfica, em que foi feito um levantamento de toda bibliografia já tornada pública em relação ao tema de estudo. A pesquisa documental também é usada, sendo fonte de coleta de dados, documentos, escritos ou não, através de documentos históricos da empresa.

\section{Referencial Teórico}

\subsection{Sistema Toyota de Produção}

Segundo Souza e Almeida [4], após o final da II Grande Guerra, em 1945, a indústria Toyota Motor Co. retomou os seus planos de tornar-se uma grande montadora de veículos. No entanto, a distância que a separava dos grandes competidores americanos era simplesmente monstruosa. Nesta época, costumava-se falar que a produtividade da mão-de-obra americana era aproximadamente dez vezes superior à produtividade da japonesa. Com isso, os japoneses se motivaram em estudar o modelo de produção americano visando alcançar, e superar, a indústria 
americana, o que de fato aconteceu anos mais tarde.

O fato da produtividade americana ser tão superior à japonesa chamou a atenção para a única explicação razoável: a diferença de produtividade só poderia ser explicada pela existência de perdas no sistema de produção japonês. A partir daí, o que se viu foi a estruturação de um processo sistemático de identificação e eliminação das perdas.

De acordo com Ohno [5], a estratégia de crescimento da empresa Toyota Motor Co., no período pós-guerra no Japão, foi a de capacitar-se para sobreviver em um mercado doméstico de demanda discreta onde a estratégia de produção em massa através da fabricação de grandes lotes, não era aplicável. A alternativa lógica foi o desenvolvimento de um sistema de produção baseado na fabricação de pequenos lotes capaz de fazer frente aos ganhos obtidos na produção em larga escala.

Revelou-se aí, a utilização de elementos inovadores que rompiam com algumas das mais básicas premissas do gerenciamento convencional. O Sistema Toyota de Produção (STP) está estruturado sobre a base da completa eliminação das perdas, com o Just in Time (JIT) e o Jidoka, que significa autonomação, atuando como seus dois pilares de sustentação, sendo demonstrado na Figura 1.

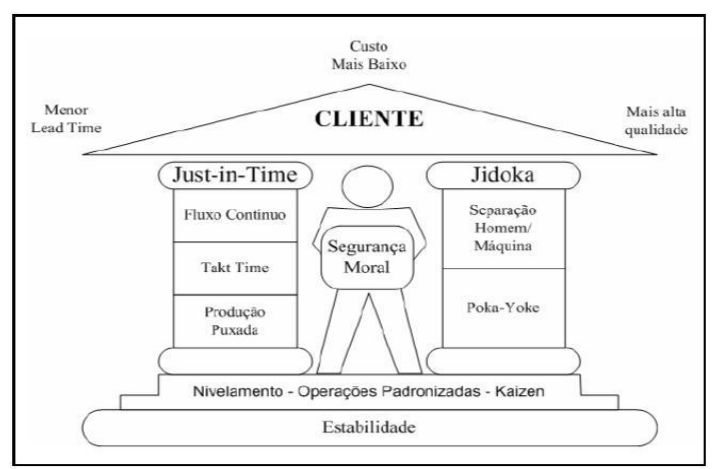

Figura 1: Estrutura do Sistema Toyota de Produção, Fonte: Almeida e Sousa (2000)

O JIT significa, que cada processo deve ser suprido com os itens e quantidades corretas, no tempo e lugar certo. É fundamental que se entenda que o JIT é somente um meio de alcançar o verdadeiro objetivo do STP que é o de aumentar os lucros através da completa diminuição das perdas. Já a Autonomação consiste em proporcionar ao operador ou à máquina a liberdade de parar o proces-samento sempre que for detectada qualquer anormalidade no sistema. Este conceito reflete a ideia de que um trabalhador pudesse operar simultaneamente mais de uma máquina, aumentando com isso a eficiência da produção. Embora a autonomação esteja frequentemente associada à automação, ela não é um conceito restrito às máquinas. É importante notar que o conceito de autonomação tem muito mais identidade com a idéia de autonomia do que com automação [6].

Com endurecimento das condições de mercado, a única forma da Toyota obter uma maior margem de lucro seria através da redução de custos e desperdícios. Para se atingir melhores níveis de produtividade foi necessário uma analise detalhada da eliminação das perdas na cadeia de valor. Isto é, fazer um diagnóstico da seqüência de processos pela qual passa o material, desde o estágio de matéria-prima até ser transformado em produto acabado. $\mathrm{O}$ processo sistemático de reconhecimento e eliminação dos danos passa ainda pela análise das operações, concentrando na identificação dos componentes do trabalho que não adicionam valor. Perdas são atividades completamente desnecessárias que geram custo, não agregam valor e que, portanto, devem ser imediatamente eliminadas. Ohno [5] classificou essas perdas presentes no sistema produtivo em sete grandes grupos: Perda por superprodução; Perda por espera; Perda por transporte; Perda no próprio processamento; Perda por estoque; Perda por movimentação; Perda por fabricação de produtos defeituosos.

Além das perdas, existem atividades que não agregam valor, mas são fundamentais para o processo, como aquelas, que também não agregam valor, e deverão ser rapi-damente eliminadas. Rother e Shook [1] idealizaram o Mapeamento do Fluxo de Valor (MFV) focando em todo o fluxo de produção de um produto ou família de produ-tos, visando à implantação da produção enxuta em todo o fluxo.

\subsection{Mapeamento do Fluxo de Valor}

Enquanto estudava as práticas de implementação enxuta da Toyota, Rother e Shook [1] perceberam o método de mapeamento de valor ao longo do fluxo. Observou-se que este possuía um potencial muito maior do que se pensava ter, http: / / dx.doi.org/10.25286/repa.v2i4.710 
então, ele formalizou a ferramenta e construiu um método de treinamento baseado no extraordinário sucesso obtido. $O$ ponto de partida essencial para o pensamento enxuto é o valor, que é todo o atributo que o cliente final está disposto a pagar por ele.

O fluxo de valor é toda ação necessária para levar um produto por todos os fluxos essenciais ao mesmo, da matéria-prima a entrega ao consumidor final. Além do fluxo de material, que é o movimento de materiais dentro da fábrica, devese levar em consideração, com a mesma importância, o fluxo de informação, que é o responsável por avisar para cada processo o que fabricar ou fazer em seguida.

Por outro lado, é uma ferramenta que, assim como as outras na produção enxuta, se concentra mais nas questões relativas à redução do lead time (dimensão tempo) dos sistemas, que parece ser a principal e, as vezes, a única dimensão considerada neste tipo de ferramenta.

A ferramenta foi construída com a finalidade de diminuir o lead time e, consequentemente, a eliminação dos desperdícios, que para Ohno [5] em todo o caso ocasionaria um impacto positivo sobre todos os objetivos de desempenho descritos por Slack et al. [7], são eles: custo, qualidade, entrega, rapidez e flexibilidade.

O mapeamento de fluxo de valor é uma ferramenta de melhoria contínua, pois como se observa na figura 2, ela cria um círculo virtuoso no qual após realizar as ações para atingir o mapa futuro, o mapa estado futuro torna-se o mapa do estado presente e serão elaboradas novas ações de melhoria para atingir o novo mapa futuro, e assim se repete o ciclo ininterruptamente.

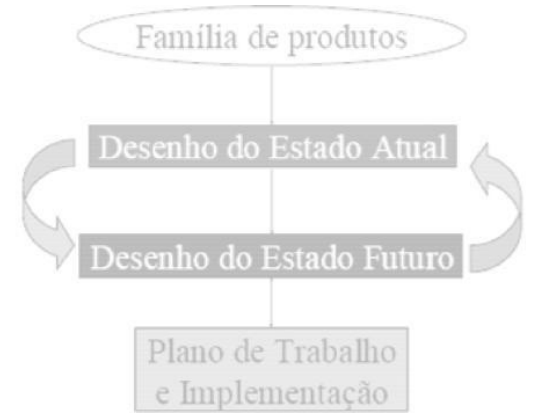

Figura 2: Ciclo de melhoria do mapeamento de fluxo de valor

Fonte: Alcantara e Silva (2016)

Lima et al [8] aplicaram o MFV, associado à simulação, numa empresa calçadista analisando os 41 impactos causados através da implementação em cenários diferentes de estado futuro observando criticamente os resultados obtidos.

Marcelino e Weiss [9] afirmam que através das intervenções propostas no sistema produtivo através da implementação do MFV numa indústria automotiva, obteve-se uma melhoria significativa nos indicadores de pontualidade de entrega dessa família de produtos.

\section{Estudo de Caso}

A empresa em questão é uma tradicional empresa americana com atuação em 30 países, que está presente no Brasil desde 1965, e conta com cerca de 6000 funcionários no país, atuando na indústria metalúrgica como produtora de alumínio, sendo responsável pela produção de $25 \%$ de todo o alumínio primário fabricado no Brasil. No mercado brasileiro, a empresa atua em toda a cadeia produtiva do metal, desde a mineração da bauxita até a produção de transformados. Em Pernambuco desde 1981, a empresa conta com duas unidades de negócio numa mesma planta no estado, atendendo a inúmeros mercados. A primeira está voltada para produtos extrudados, que são destinados aos setores de construção civil, transportes, equipamentos, elétricos e bens de consumo. A segunda unidade de negócio é responsável pela produção de laminados, que são utilizados na indústria alimentícia e farmacêutica, na forma de embalagens, construção civil e naval, setor automobilístico e produção de eletrodomésticos.

O presente trabalho foi desenvolvido na segunda unidade de negócios, a responsável pela fabricação de produtos laminados. A produção desta unidade pode ser dividida em famílias de produtos: folhas, chapas e telhas de alumínio. Esta divisão se dá principalmente pela espessura do produto final, além da forma do material. A fábrica é dividida em três grandes áreas: Refusão, Chapas e Folhas. O fluxo de produção desta fábrica pode ser entendido de forma genérica através da figura 3. A produção se inicia com o consumo de lingotes de alumínio pela refusão, onde são processados nos fornos de fusão junto com outros componentes, que formam a liga de alumínio a ser requisitada. Após a fusão é formada a primeira bobina de alumínio, com uma espessura ainda muito alta. Estas bobinas são enviadas para a Laminação de Chapas e para a Laminação de 
Folhas, onde serão submetidas a processos produtivos específicos, como a laminação para o alcance de espessuras menores, ou então tratamentos térmicos, que permitem que 0 material apresente diferentes propriedades mecânicas, de acordo com as especificações necessárias.

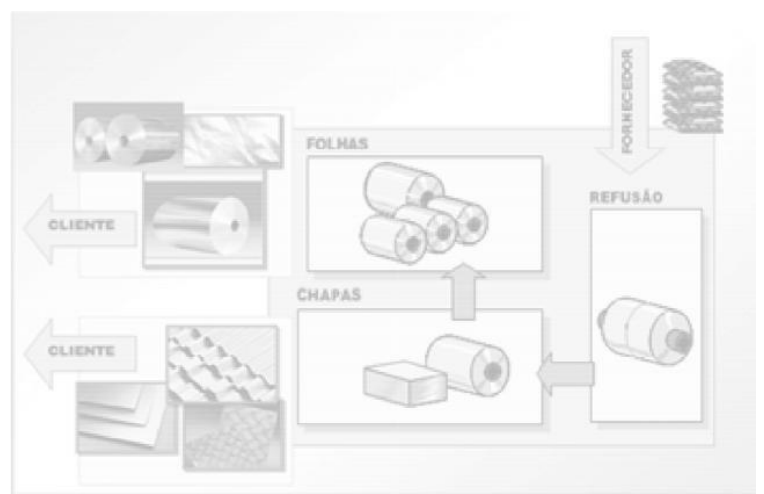

Figura 3: Fluxo de produção da planta Fonte: Dados da empresa

As perspectivas do mercado de alumínio vêm crescendo devido à ascendência das indústrias de bens de consumo, além de algumas alterações externas no mercado. A fábrica deste estudo de caso apresenta hoje uma demanda mensal de cerca de quatro mil toneladas de produtos laminados: folhas, chapas e telhas. Desta forma, para que a empresa possa melhorar o desempenho operacional em suas linhas de produção se fez necessário o emprego de algumas ferramentas gerenciais. A empresa tem seu próprio sistema de gerenciamento baseado no Sistema Toyota de Produção implantado em todas as unidades da empresa a nível mundial, buscando a eliminação de desperdício através da melhoria contínua.

$\mathrm{O}$ estudo foi desenvolvido em uma máquina laminadora da laminação de Folhas, que tem como característica laminar bobinas para espessura solicitada pelo processo ou pelo cliente.

Foi realizado um estudo em cima do setup de troca de bobina (TTB) da laminadora, avaliando o tempo gasto com esta atividade. A princípio, realizou-se um trabalho de acompanhamento do processo, pois não existia um padrão para o procedimento atual realizado. A partir desse ponto ocorreu uma análise dos dados obtidos e construído o padrão para a ativida de de troca de bobina da forma que era realizada pela operação, atingindo 16,2 min de setup. A figura 4 descreve o mapeamento de fluxo de valor atual.

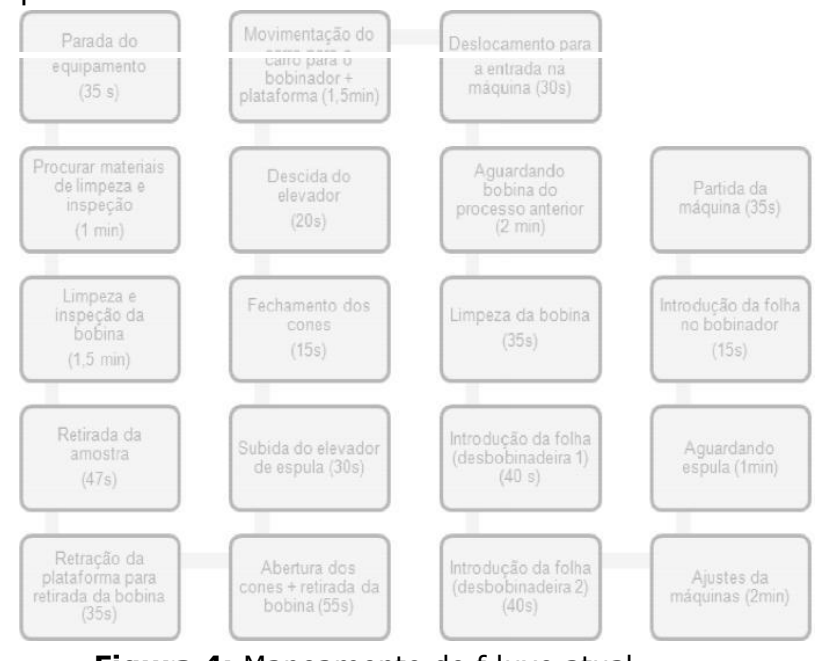

Figura 4: Mapeamento do f luxo atual Fonte: Dados da empresa

A redução no tempo de máquina parada implica num maior tempo de máquina produzindo volume de material acabado, e assim ganho financeiro para empresa que estará aproveitando melhor seus recursos físicos.

Dessa forma, efetuou-se uma análise critica do mapeamento de processo atual, verificou-se que existiam atividades que não agregavam valor e, assim, foi proposto o novo fluxo de processo, representa do na figura 5 , com a exclusão dos processos que representavam desperdícios de tempo, apresentando redução no tempo de setup e ganho de produtividade.

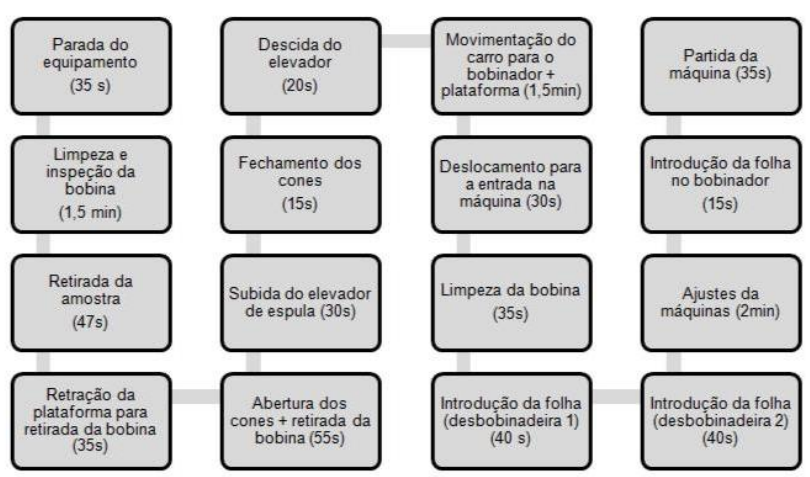

Figura 5: Mapeamento do fluxo proposto Fonte: Dados da empresa

As atividades excluídas (Procurar materiais de limpeza e inspeção, Aguardando bobina do processo anterior, e Aguardando espula) do mapeamento atual são operações que, não agregam valor ao processo principal, devem ser 
feitas antes que a troca de bobina se inicie, ou seja, já devem estar prontos em espera para o início do setup, chama-se também de setup externo, em que acontece fora do setup principal. Os materiais de limpeza e inspeção devem estar em local predefinido próximo a área de utilização; a bobina do processo anterior deve estar disponível na máquina antes do setup se iniciar, da mesma forma que a espula, pois são essenciais ao processo.

O mapeamento de processo proposto reduziu o tempo de máquina parada em aproximadamente $25 \%$ de $16,2 \mathrm{~min}$ para $12,2 \mathrm{~min}$. Dessa maneira, iniciou-se o trabalho posterior de treinamento da equipe para se atingir o TTB de 12,2 min. Para o desenvolvimento da operação é necessário alguns meses de treinamento diário para nivelar todos eles no mesmo conhecimento e cumprimento do padrão. Os treinamentos iniciaram-se em Janeiro/2016 e no mês de Maio/2016 atingiu-se o TTB proposto.

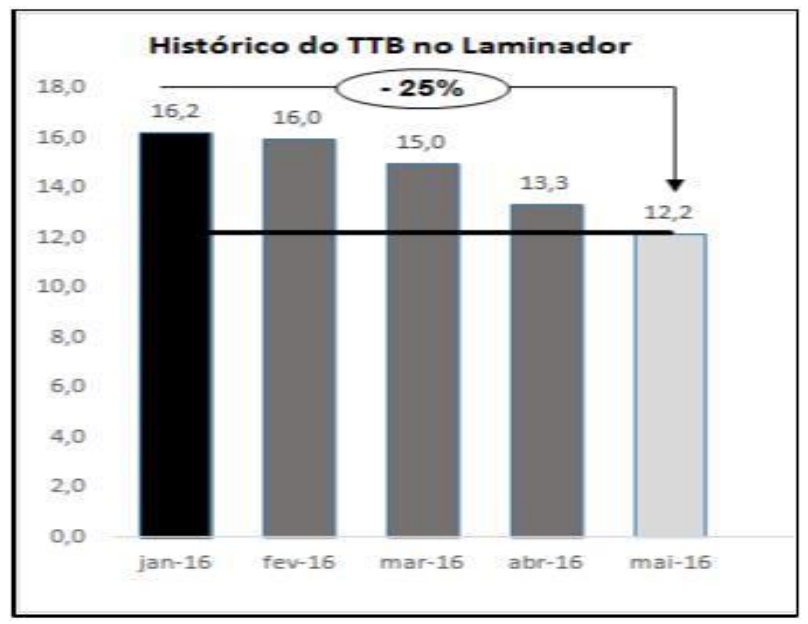

Figura 6: Histórico dos tempos de TTB Fonte: Dados da empresa

Através do acompanhamento realizado no início do trabalho, alguns dados foram obtidos, inicialmente, para calcular os benefícios adquiridos após o alcance do objetivo, são eles:

- O número médio de ocorrências de troca de bobina no mês: 168 vezes;

- O custo médio: $\mathrm{R} \$ 749,62$ por tonelada (ton);

- Produtividade média: 3 ton/hora.

A partir dos dados apresentados pode-se fazer a comparação do custo médio de máquina parada através do método atual e o proposto, e com a redução de 4 min de tempo de parada, obteve um ganho financeiro mensal de $R \$ 25.153,94$, ou seja,
$\mathrm{R} \$ 301.847,31$ anual, demonstrado na Tabela 1. Além dos ganhos finaceiros, conquistou-se também, benefícios não-financeiros, como a criação de um procedimento padrão para atividades, o nivelamento do conhecimento entre toda a operação, e desenvolvimento de habilidades dos funcionários.

Tabela 1: Custo e Beneficios com a redução do TTB

\begin{tabular}{|c|c|c|c|c|}
\hline \multicolumn{5}{|c|}{ Cálculo dos Benefícios com Redução do TTB } \\
\hline & \multicolumn{2}{|c|}{ Método Atual } & \multicolumn{2}{|c|}{ Método Proposto } \\
\hline Custo médio (RS/ton) & RS & 749,62 & $R \$$ & 749,62 \\
\hline Produtividade (ton/h) & & 3,0 & & 3,0 \\
\hline Tempo médio de TTB (min) & & 16,2 & & 12,2 \\
\hline Número de ocorrências de TTB (unid.) & & 168 & & 168 \\
\hline Impacto financeiro do $T \pi 8$ (RS) & RS & $101.873,47$ & $R \$$ & $76.719,52$ \\
\hline Ganho Mensal (R\$) & & & RS & $25.153,94$ \\
\hline Ganho Anual (R\$) & & & RS & $301.847,31$ \\
\hline
\end{tabular}

Fonte: Dados da empresa

As melhorias relatadas ratifica o objetivo da empresa de descobrir as oportunidades internas para reduzir seus custos eliminado desperdícios e assim continuar satisfazendo as necessidades dos clientes e ao mesmo tempo gerar lucros significativos à empresa, afinal, conforme descreve Chiavenato [10], "negócio é um esforço organizacional, por determinadas pessoas para produzir bens e serviços, a fim de vendê-los em um determinado mercado e alcançar recompensa financeira pelo seu esforço."

\section{Considerações Finais}

Devido ao atual ambiente de competitividade exigido pelo mercado, cresce a importância dada pelas grandes companhias a novas ferramentas de gestão que garantam sistemas mais enxutos e consistentes.

Pretendeu-se com o presente trabalho, melhor entender a filosofia do Sistema Toyota de Produção, assim como, apresentar o Mapeamento do Fluxo Valor, uma ferramenta capaz de auxiliar na identificação dos desperdícios que ocorrem no processo produtivo, e assim, facilita na redução do lead time em uma linha de produção. O sucesso desta ferramenta nas diversas empresas que o adotam pode ser justificado pela linguagem simples para entendimento e facilidade na utilização de representar os processos da manufatura.

Com a aplicação da ferramenta MFV num processo produtivo na indústria de alumínio, 
visualizou-se as perdas que ocorriam no método realizado, que eram as esperas por recursos necessários no processo principal. A comparação entre os estados atual e proposto mostrou a proporção das melhorias implementadas, através da redução do tempo de setup e benefícios financeiro para a empresa.

\section{Referências}

[1] M. Rother, J. Shook. Aprendendo a enxergar - mapeando o fluxo de valor para agregar valor e eliminar o desperdício. Lean Institute Brasil, São Paulo, 2003.

[2] M. A. Marconi, E. M. Lakatos. Fundamentos de metodologia. 5. Ed. Atlas, São Paulo, 2003.

[3] P. A. C. Miguel(org). Metodologia de pesquisa em engenharia de produção e gestão de operações. 2. Ed. Elsevier, ABEPRO, Rio de Janeiro, 2012.

[4] A. T. Almeida, F. M. C. Souza. Produção \& Competitividade: Aplicações e Inovações, Ed. da UFPE, Recife, 2000.

[5] T. O. Ohno. Sistema Toyota de Produção: além da produção em larga escala. 5. ed. Bookman, Porto Alegre, 1997.

[6] P. Ghinato. Sistema Toyota de Produção: mais do que simplesmente just-in-time. 1 ed. EDUSC, Caxias do Sul, 1996.

[7] N. Slack, S. Chambers, R. Johnston. Administração da Produção. Editora Atlas, São Paulo, 1996.

[8] D. F. S. Lima, P. G. F. Alcantara, L. C. Santos, L. M. F. Silva, R. M. Silva. Mapeamento do fluxo de valor e simulação para implementação de práticas lean em uma empresa calçadista; Revista Produção Online, V. 16, N. 1 (2016).

[9] H. P. Marcelino, J. M. G. Weiss. Melhoria de processos por meio do mapeamento do fluxo de valor: estudo de caso. In: Encontro Nacional de Engenharia de Produção, Salvador, 2009.
[10] I. Chiavenato. Administração de produção: uma abordagem introdutória. Ed. Elsevier, Rio de Janeiro, 2005. 